20 Biofiltration has been established as a promising alternative to conventional air 21 pollution control technologies. However, gas biofilter modeling has been less developed

\section{Modeling of a bacterial and fungal biofilter applied to toluene abatement: kinetic} parameters estimation and model validation Antoni David Dorado*, Guillermo Baquerizo*, Juan Pedro Maestre**, Xavier

*Department of Mining Engineering and Natural Resources, Universitat Politècnica de 7 **Department of Chemical Engineering, Universitat Autònoma de Barcelona, Edifici C, 08193 Bellaterra, Barcelona, Spain Corresponding author e-mail: xavierg@emrn.upc.edu

\section{ABSTRACT} than experimental research due to the complexity of describing the fundamental 23 processes and the lack of globally accepted physical, chemical and biological 4 parameters. In addition, biofiltration modeling based on degradation activity of fungi 25 has been rarely considered. For this reason, in this work, a dynamic model describing 
1 toluene abatement by a bacterial and fungal biofilter is developed, calibrated and

2 validated. The mathematical model is based on detailed mass balances which include

3 the main processes involved in the system: convection, absorption, diffusion and

4 biodegradation. The model was calibrated and validated using experimental data

5 obtained from two equal lab-scale biofilters packed with coconut fiber and pine leaves,

6 respectively. Both reactors were operated under similar conditions during 100 days at an

7 empty bed residence time of 60 seconds and an average inlet load of $77 \mathrm{~g}$ toluene $\mathrm{m}^{-3} \mathrm{~h}^{-}$

81 . Biofilters were initially inoculated with a bacterial consortium, even though reactors

9 were mostly colonized by fungi after 60 days of operation according to microscopic

10 observation and reactors $\mathrm{pH}$. Removal efficiency increased notably from $20 \%$ for the

11 bacterial period to $80 \%$ for the fully developed fungal biofilters. Since kinetic

12 parameters are strongly dependent on the biological population, semi-saturation

13 constants for toluene and maximum growth rates were determined for bacterial and

14 fungal operation periods. Kinetic parameters were fitted by means of an optimization

15 routine using either outlet concentrations or removal efficiency data from the coconut

16 fiber biofilter. A novel procedure in gas biofilters modeling was considered for

17 checking the model calibration, by the assessment of the parameters confidence interval

18 based on the Fisher Information Matrix (FIM). Kinetic parameters estimated in the

19 coconut fiber reactor were validated in the pine leaves biofilter for bacterial and fungal

20 operation. Adequate model fitting to the experimental outlet gas concentration for both

21 bacterial and fungal operation periods was verified by using a standard statistical test.

23 Keywords: kinetic parameters estimation, modeling, toluene abatement, fungal 24 biofilters, confidence interval, Fisher Information Matrix. 


\section{INTRODUCTION}

2

3 Traditionally physical and chemical processes have been applied to treat polluted air

4 emissions. However, the high costs of operation and energy consumption associated to

5 conventional treatments have lead to increase the attention on biological processes.

6 During the last years biofiltration has emerged as an efficient and reliable biological

7 process to treat pollutants from contaminated air emissions. This technology has been

8 successfully used to remove a wide range of pollutants such as volatile organic

9 compounds (VOCs), ammonia and sulphurous compounds, amongst others $[1,2,3,4]$.

11 In general, a biofilter consists in a reactor packed with a carrier material (organic or 12 inorganic) serving as a support for biofilm growth. The contaminated air stream to be 13 treated is passed through the fixed-bed and the pollutant is transferred from the gas to 14 the biofilm by absorption. In the biofilm, diffusion and biodegradation take place 15 simultaneously. Thus, biofiltration employs the metabolic activity of microorganisms to 16 degrade pollutants which are the energy source for microbial growth. Bacteria and fungi 17 are definitely the two dominant microorganisms in biofilters but depending on the 18 biofilter operation microorganisms may develop according to their capacities to adapt to 19 the biofilters ecosystem [5]. Bacteria normally present a rapid substrate uptake and 20 growth. Under favourable conditions bacteria will be the dominant consortia, even 21 though fungi may be also present. On the other hand, fungi generally grow slower than 22 bacteria, but they are capable of degrading a broad variety of pollutant and can 23 withstand with more adverse conditions [6,7]. 
1 High moisture content in the biofilter must be kept in order to maintain

2 biodegradation activity. Usually, the moisture content in the biofilter is achieved by

3 humidifying the air stream before entering the reactor and/or sprinkling water from the

4 top of the biofilter periodically. Additionally, watering is employed to remove the

5 excess of biomass and to avoid clogging episodes and toxics accumulation within the

6 reactor [8,9]. Generally, micronutrients are supplied during watering periods to support

7 microbial activity.

9 Toluene abatement by biofiltration has been widely investigated using biofilters 10 inoculated with bacterial consortia $[10,11]$. Several packing materials and operating 11 conditions have been employed to study toluene removal performance. Recently, 12 biofiltration based on the degradation activity of fungi has been satisfactorily applied to 13 treat both slight and considerable hydrophobic compounds such as toluene, hexane and $14 \quad \alpha$-pinene $[5,12,13,14,15]$.

16 In the case of toluene, results have demonstrated that fungal biofilters are capable of 17 obtaining higher elimination capacities than biofilters based on bacterial activity. Weber and Hartmans (1996) reported a larger elimination capacity in a biofilter inoculated with

19 fungi (45 $\left.\mathrm{g} \mathrm{m}^{-3} \mathrm{~h}^{-1}\right)$ instead of one inoculated with bacteria $\left(28 \mathrm{~g} \mathrm{~m}^{-3} \mathrm{~h}^{-1}\right)$. Likewise 20 Maestre et al. (2007) studied the performance of four organic packing materials in 21 biofilters inoculated with activated sludge from an urban wastewater treatment plant. An 22 enhancement of removal efficiencies (RE > 80\%) and EC up to $95 \mathrm{~g} \mathrm{~m}^{-3} \mathrm{~h}^{-1}$ were 23 obtained when biofilters evolved from neutral to acidic $\mathrm{pH}$ (i.e. when the consortium in 24 the packed bed switched to fungi). In their experiments, Garcia-Peña et al. (2001) and 25 Woertz et al. (2001) obtained removal efficiencies up 95\% with maximum toluene 
1 elimination capacities in the range of $258-270 \mathrm{~g} \mathrm{~m}^{-3} \mathrm{~h}^{-1}$ which is 2 to 7 times greater than

2 the elimination capacities typically reported for bacterial-based biofilters.

4 Several hypotheses have been provided to explain the superior performance of 5 fungal biofilters in comparison to biofilters based on bacterial activity. It has been 6 reported that bacterial biofilter stability is often hindered by the poor absorption of 7 pollutants on the biofilm besides acidification and drying out of the filter bed [7]. 8 Fungal population presents several advantages due to their ability to tolerate acidic and 9 dryer conditions than bacteria $[18,19,20]$. Additionally, it has been hypothesized that 10 aerial mycelia of fungi can take up pollutants faster than flat, aqueous biofilm surfaces 11 in the case of hydrophobic compounds [7,15,21]. Also, it has been recently suggested 12 that a greater affinity of hydrophobic pollutants (i.e. air/biofilm partition coefficient) is 13 encountered in fungal biomass rather than bacterial biofilms [21,22]. As a drawback, 14 releasing of spores to the environment may occur in cases of severe drying.

16 Some of the main purposes of modeling are to organize experimental data, to 17 understand simple relationships between parameters and pollutant removal, to design equipments according to a specific operation, to predict the performance under given 19 conditions and to perform processes optimization [4]. In any case, biofiltration 20 modeling has received less attention in comparison to experimental approaches.

21 Numerous studies dealing with mathematical models of toluene removal by biofiltration

22 can be found in literature. Simple and complex models have been employed to emulate 23 toluene biofiltration under both steady-state and dynamic operating conditions $24[23,24,25,26,27,28]$. In all modeling works reported in the literature toluene removal in 
1 biofilters is based on bacterial degradation activity without taking into account fungal

2 operation.

3

4 In addition, kinetic parameters (i.e yield coefficient or biomass concentration) are 5 frequently taken from the literature in which experimental conditions may be 6 considerably different and the results may vary significantly. Although direct 7 experimental determination of kinetic parameter is not a trivial task due to the difficulty 8 to reproduce experimental system, it must be stressed the necessity to calibrate each

9 model for each specific experimental conditions instead of using the values of 10 parameters reported in previous works. Only a reduced number of studies have dealt 11 with direct calculation of kinetic parameters from experimental data by using complex 12 determination routines [29,30], even though the results obtained were close to those 13 obtained by curve fitting experimental data using classical optimization routines. On the 14 other hand, in biofiltration, unlike water treatment, the interval of confidence in the 15 model parameters estimation has not been commonly assessed, even though it should be 16 as important as the estimation of the parameter values themselves [31].

18 The aim of this work was to contribute to the general understanding on how 19 switching populations from bacteria to fungi can be modelled in a biofilter. Taking this 20 into consideration, in this work, a general dynamic biofiltration model applied to 21 toluene removal is developed, calibrated and validated. Mathematical equations are 22 based on discretized mass balances taking into account the main chemical and physical 23 phenomena involved in the system. Previous experimental results obtained previously 24 [12] in which a toluene degrading biofilter inoculated with microbial populations 25 evolved to a fungal biofilter were used herein as input data to calibrate and validate a 
1 biofiltration model. In addition a statistical procedure is applied to check the confidence

2 intervals of the parameters obtained during the model calibration procedure. Finally a

3 rigorous statistical test is used in order to assess the accuracy of model predictions.

\section{MATERIALS AND METHODS}

6

7

Experiments were carried out using a lab-scale plant consisting of two PVC columns with an inner diameter of $8.6 \mathrm{~cm}$ and a height of $90 \mathrm{~cm}$ (Figure 1). Reactor 1 and Reactor $2\left(R_{1}\right.$ and $\left.R_{2}\right)$ were packed with coconut fiber and pine leaves respectively, to a height of $50 \mathrm{~cm}$ meaning a total bed volume of $2.9 \mathrm{~L}$ each one. Water content was kept around $80 \%$ in $\mathrm{R}_{1}$ and $70 \%$ in $\mathrm{R}_{2}$, while the organic matter content prior to biofilters startup was $80 \%$ in the former and $90 \%$ in the latter.

As shown in Figure 1, a primary air stream passed through two water columns in series in order to increase the inlet air relative humidity up to $90 \%$. A secondary air stream was pumped by a peristaltic pump (Masterflex L/S) into a glass bubbler unit of $200 \mathrm{ml}$ of volume containing pure liquid toluene (Panreac 99.5\%). Both gaseous flowrates were mixed in a mixing chamber and the resulting gas mixture was fed from the base of the reactor. Throughout this study, the gaseous stream was supplied in upflow mode to obtain homogeneous humidity conditions and avoid a long residence time of secondary products in the bed [4]. The outlet gas stream was passed through an activated carbon vessel to retain any remaining pollutant. Pressure drop across the fixed-bed reactor was measured in the gas phase by means of a water-filled U-tube manometer. Also the reactors weight was periodically measured during the experimental period. 
2 In order to keep a suitable moisture content, provide the necessary nutrients for the

3 microorganisms and wash out dead cells and end-products of toluene degradation, tap

4 water or a nutrient solution was automatically sprinkled daily over the biofilter beds at a

5 flowrate of $200 \mathrm{~mL} \mathrm{~d}^{-1}$ by means of a diaphragm dosing pump (Alldoss, Primus 221).

6 The nutrient solution was composed by $\mathrm{KH}_{2} \mathrm{PO}_{4}\left(1 \mathrm{~g} \mathrm{~L}^{-1}\right), \mathrm{K}_{2} \mathrm{HPO}_{4}\left(1 \mathrm{~g} \mathrm{~L}^{-1}\right), \mathrm{NH}_{4} \mathrm{Cl}(1$

$\left.7 \mathrm{~g} \mathrm{~L}^{-1}\right), \mathrm{NaCl}\left(1 \mathrm{~g} \mathrm{~L}^{-1}\right), \mathrm{MgSO}_{4}\left(0.2 \mathrm{~g} \mathrm{~L}^{-1}\right), \mathrm{CaCl}_{2}\left(0.02 \mathrm{~g} \mathrm{~L}^{-1}\right)$ and trace elements $(1 \mathrm{~mL}$

$8 \mathrm{~L}^{-1}$ ). Periodically the excess of solution (leachate) was manually collected at the bottom

9 section to report measurement of the medium $\mathrm{pH}$.

11 A structured control system with a PLC (Siemens, S7-314C-2DP) and a commercial

12 SCADA software (Siemens, WinCC v.5.2) were used to automate the pilot-plant. The

13 system was used for regulating the water addition and to monitor the inlet gas

14 temperature and relative humidity (Testo, Hygrotest 600 PHT).

16 Gas samples were collected from sampling ports at the inlet and outlet of each

17 reactor by means of Tedlar® bags. Toluene concentration was measured in triplicate in each port using a gas chromatograph (series 6890N GC, Agilent Technologies) equipped with a capillary column (HP-5, Agilent technologies) and a flame ionization 20 detector (FID). 
MODEL DEVELOPMENT

4

5 The model was built considering the most relevant phenomena occurring during the 6 biofiltration process like convection, absorption, diffusion and biodegradation. The

7 theoretical model describing the elimination of toluene in a biofilter bed is based on the

8 mass balance in the gas phase and within the biofilm. Important assumptions underlying

9 the model are based on consolidate models reported [3,26,27,32]:

10

11 (1) Gas phase circulation regime is modelled as plug flow pattern. Thus, axial 12 dispersion is not considered.

13 (2) Gas-biofilm interface equilibrium is described by Henry's law.

14 (3) Planar geometry and perpendicular diffusion in biofilm are used to derive model

15 equations considering that the solid support size is significantly higher than the

16 biofilm thickness. Diffusion in the biofilm is described by Fick's law.

17 (4) Biofilm is formed on the external surface of the packing material. Thus, biomass

18 does not grow in the pores of the packing material and reactions only take place in 19 the biofilm phase.

20 (5) Physical properties of the species in the biofilm are assumed to be the same as in 21 water since this is the main component.

22 (6) There is no accumulation of biomass in the filter bed in each period and biomass 23 properties (thickness, specific surface area and kinetic coefficients) are uniform 24 along the bed. This assumption was experimentally verified by monitoring a 
practically constant pressure drop and reactor weigh in the whole studied operation period as shown in Maestre et al. (2007).

3 (7) Adsorption of pollutant onto the support is neglected due to the low pollutant concentration and the low adsorption capacity of the packing material. Moreover, under steady-state conditions, the adsorption process is in equilibrium [27].

Mass balance in the bulk gas phase

8

$\frac{\partial C_{g}}{\partial t}=-v_{z} \frac{\partial C_{g}}{\partial z}-\frac{N_{g-b} \cdot a}{\varepsilon}$

with boundary conditions:

at $\mathrm{z}=0$,

$C_{g}=C_{g i}$

11 where $C_{g}$ is the concentration of toluene in the gas phase in $\mathrm{g} \mathrm{m}^{-3} ; v_{z}$ is the interstitial 12 gas velocity in $\mathrm{m} \mathrm{h}^{-1}, C_{g i}$ is the inlet gas concentration in $\mathrm{g} \mathrm{m}^{-3}, z$ is the position along 13 the biofilter height in $\mathrm{m}, N_{g-b}$ is the specific mass flux from the gas to the biofilm phase 14 for toluene in $\mathrm{g} \mathrm{m}^{-2} \mathrm{~h}^{-1} ; a$ is the specific surface area (surface area per unit volume of bed 15 reactor) in $\mathrm{m}^{2} \mathrm{~m}^{-3}$ and $\varepsilon$ is the bioreactor bed porosity. Interstitial gas velocity is 16 calculated considering the porosity of the reactor bed (Eq. 2) and the mass flux given by 17 Fick's law (Eq. 3).

$$
v_{z}=\frac{Q_{g}}{A \cdot \varepsilon}
$$




$$
N_{g-b}=-\left.D\left(\frac{\partial C_{b}}{\partial x}\right)\right|_{x=0}
$$

2 where $Q_{g}$ is the volumetric air flow in $\mathrm{m}^{3} \mathrm{~h}^{-1} ; A$ is the cross-section area of the

3 bioreactor in $\mathrm{m}^{2} ; D$ is the diffusion coefficient in $\mathrm{m}^{2} \mathrm{~h}^{-1}, C_{b}$ is the pollutant

4 concentration in the biofilm phase in $\mathrm{g} \mathrm{m}^{-3}$; and $x$ is the position in the biofilm from the

5 surface in $\mathrm{m}$.

6

$7 \quad$ Mass balance in the biofilm phase

8

9 Model equation for the biofilm under dynamic conditions is shown in Eq.4.

$$
\frac{\partial C_{b}}{\partial t}=D \frac{\partial^{2} C_{b}}{\partial x^{2}}+r
$$

with boundary conditions: $\quad$ at $\mathrm{x}=0, \quad C_{b}=C_{g} / H$

$$
\text { at } \mathrm{x}=\delta, \quad \frac{\partial C_{b}}{\partial x}=0
$$

11 where $r$ is the substrate consumption rate in $\mathrm{g} \mathrm{m}^{-3} \mathrm{~h}^{-1} ; \delta$ is the biofilm thickness in $\mathrm{m}$ and $12 H$ is the gas-liquid distribution coefficient given by Henry's law.

\section{Kinetic expression}

16 Several kinetic expressions have been used in VOCs degradation by biofiltration

17 such as zero or first-order kinetics depending on the pollutant concentration in the 18 biofilter [26,33]. Haldane-type kinetics have been also used for modeling interaction 
1 between pollutants during the biological degradation in the biofilm [34]. Currently, in

2 most of works, the specific consumption rate for toluene degradation is described by a

3 Monod-type kinetic expression as this work considers (Eq. 5).

$$
r=v_{\max } \frac{C_{b}}{K_{S}+C_{b}}
$$

4

5 where $K_{S}$ is the semi-saturation or affinity constant in $\mathrm{g} \mathrm{m}^{-3}$ and $v_{\max }$ is the volumetric 6 maximum growth rate in $\mathrm{g} \mathrm{m}^{-3} \mathrm{~h}^{-1}$ as described in Eq. (6):

$$
v_{\max }=\mu_{\max } \frac{X}{Y_{P}}
$$

8 where $\mu_{\text {max }}$ is the specific growth rate in $\mathrm{h}^{-1}, X$ is the biomass density in $\mathrm{g} \mathrm{m}^{-3}$ and $Y_{P}$ is

9 the biomass to substrate yield coefficient. The volumetric kinetic expression is generally

10 used in biofilter modeling due to the difficulty to determinate the biomass density in the

11 system with a non-destructive technique and without modifying experimental

12 conditions. Moreover, $\mu_{\max }$ and the active fraction of the degrading biomass separately

13 are not identifiable. Consequently, there is not a unique parameter set able to describe

14 the behaviour of the system and lumped parameters have to be estimated together [35].

16 In this case, oxygen limitation was not included in the kinetic expression because of the

17 low pollutant concentration, the low biofilm thickness and the hydrophobic character of

18 toluene. Previous simulations (results not shown) were performed to confirm that

19 oxygen consumption was not a limiting process in the degradation of toluene. Oxygen

20 concentration in the biofilm was superior to $5.5 \mathrm{~g} \mathrm{~m}^{-3}$ under the maximum oxygen

21 consumption rate. Thus, oxygen was not depleted in the whole biofilm thickness and 
1 oxygen concentration was high enough to have no influence on the toluene consumption

2 rate. Otherwise, a Monod term including oxygen concentration should be added in a 3 multisubstrate type kinetics.

4

5 Moreover, it must be stressed that other phenomena that affect the degradation rate

6 such as nutrient limitation might be present in the kinetic of the model. In the present

7 work, the effect of nutrient concentration was lumped into the volumetric maximum

8 growth rate in the kinetic expression. Either provided by the packing material or

9 externally fed through the watering system, nutrient concentration was considered to be

10 constant along the height of the reactor during biofilters operation.

\section{Mathematical solution}

The set of partial differential equations was discretized in space along the bed height and biofilm thickness. The conversion of the tubular reactor into serial stirred reactors was checked. An optimal discretization of the biofilter was found resulting in eight nodes along the bed height and eight nodes along the biofilm thickness.

The resulting set of ordinary differential equations was solved using MATLAB in a home-made modeling environment. A variable order method was used for solving stiff

21 differential equations based on the numerical differentiation formulas (NDFs), which

22 are generally more efficient than the closely related family of backward differentiation

23 formulas (BDFs), also known as Gear's methods. The time step used in the numerical

24 solution routine was established in 1 hour, which was significantly lower than the time

25 interval of the experimental data (i.e normally higher than 24 hours). Since the inlet 
1 toluene concentration and inlet gas flow changed along biofilters operation, a linear

2 interpolation was considered for the time interval comprised between two consecutive 3 inlet data.

4

Model calibration and validation

6

7 In the model calibration step, the volumetric maximum growth rate and the saturation

8 constant were the set of parameters to estimate. To start with the procedure, initial

9 guesses were assigned to kinetic parameters according to the literature. Predicted outlet

10 concentrations by the model were compared with the experimentally measured data and

11 the deviations between both were used to obtain updates for kinetic parameters. The

12 values of parameters were sought to minimize the objective function $(O F)$ given in Eq.

13 (7) for each period simulated.

$O F=\sqrt{\sum_{i=1}^{N}\left[C_{g, \text { out }}\left(p_{1}, p_{2}\right)-C_{g, \text { out }}^{*}\right]^{2}}$

16 where $C_{g, \text { out }}$ is the outlet concentration of toluene in gas phase predicted by the model

17 in $\mathrm{g} \mathrm{m}^{-3} ; p_{1}$ and $p_{2}$ are the unknown parameters to fit; $C_{g, \text { out }}^{*}$ is the outlet concentration

18 of toluene experimentally measured in gas phase in $\mathrm{g} \mathrm{m}^{-3}$, and $\mathrm{N}$ is the total number of 19 data sets.

The parameter estimation was performed using a MATLAB algorithm based on a 22 multidimensional unconstrained nonlinear minimization (Nelder-Mead). This is a direct 23 search method that does not use numerical or analytical gradients. 
2 Regarding confidence intervals of estimated parameters, these were assessed through

3 a numerical method based on the Fisher Information Matrix (FIM) [36,37]. The FIM

4 matrix is related to the quantity and quality of information obtained from experiments

5 and considers the sensitivity of optimized parameters and the measurement errors of the

6 experimental data. Assuming white measurement noise and no model mismatch, the

7 inverse of the FIM provides the lower bound of the parameter estimation covariance

8 matrix, which can be used for assessing the estimation uncertainty of the parameters.

9 Moreover, since output sensitivities of parameters are calculated using a model, the FIM

10 also depends on the structure of the model. This property has widely been used to study

11 the practical identifiability of the models under the available experimental data in the

12 field of wastewater treatment [37] but previous works have not been found in gaseous

13 pollutant modeling. Model validation of the present work was checked by performing a

14 statistic analysis based on a paired t-student test at 5\% level of significance.

17 RESULTS AND DISCUSSION

Experimental conditions

The calibration and validation of the developed dynamic model was carried out 22 using part of the experimental data of the previous work of Maestre et al. 2007, in which performance of four organic packed biofilters was studied under different operation conditions in a period of 240 days. The suitability of the different packing materials was compared for the treatment of toluene. In the work presented herein, the 
1 first 100 days of operation of two out of the four biofilters were chosen for modeling

2 purposes. In this period, reactors were operated at average inlet load of $77 \mathrm{~g}$ toluene $\mathrm{m}^{-3}$

$3 \mathrm{~h}^{-1}$ at an EBRT of $60 \mathrm{~s}$.

4

5 Reactors were initially inoculated with activated sludge from a municipal 6 wastewater treatment plant and operated during the first 50 days as bacterial biofilters.

7 After 50 days of operation the $\mathrm{pH}$ dropped at values as low as 3 and fungal activity was

8 detected proving both biofilters evolved from bacteria to fungal reactors [13]. It is

9 hypothesized that the $\mathrm{pH}$ decrease is related to the production of acidic by-products

10 such as benzoic acid, which arise from toluene degradation [38]. Simultaneously, a 11 notable increment of removal efficiency (RE) from around $20 \%$ to $80 \%$ was observed 12 along the operation time in both biofilters (Figure 2), which was related to an increment 13 on the amount of nutrients provided after day 44.

\section{Figure 2}

21 Three different operation periods were identified and used for modeling purposes. In 22 each selected period a pseudo steady-state operation was experimentally verified. Thus, 23 pseudo steady-state conditions were assumed for biomass accumulation in each period 24 to perform parameter determination and further model validation. In the first period 25 (from day 22 to 38 ), namely Period A, a watering rate of $200 \mathrm{~mL} \mathrm{~d}^{-1}$ of tap water was 
1 supplied. Thus, watering was only used in order to keep suitable moisture in the system.

2 During the Period A, the $\mathrm{pH}$ in the collected leachate was near the neutrality for both

3 reactors. No fungal colonies were observed during Period A. In the second period (from

4 day 50 to 66 ), namely Period $B, 200 \mathrm{~mL} \mathrm{~d}^{-1}$ of a nutrient solution were supplied in

5 excess due to the low removal efficiency achieved in Period A. A transition from

6 bacterial to fungal reactor was identified in both reactors by microscopic observation,

7 which correlated well with the decrease in the $\mathrm{pH}$ observed in both reactors (Figure 2).

8 A third and last period (from day 78 to 94), namely Period $C$, was mainly carried out by

9 fungal consortia according to microscopic observations. In a previous work, two fungal

10 genus were isolated and recognised as Aureobasidium sp. and Clonostachys sp [12].

11 The $\mathrm{pH}$ measured in the leachate was below 3 in Period $C$, which hindered the presence

12 of other kind of microorganisms in the medium. The watering rate and nutrient supply

13 was kept for both reactors with the purpose of ensuring an excess of nutrients.

Kinetic parameter determination

17 Since both reactors were operated under identical loading and EBRT conditions, 18 kinetic parameters may be determined using experimental data from either reactor $\mathrm{R}_{1}$ or $19 \mathrm{R}_{2}$. Thus, kinetic parameters were calculated using experimental data from reactor $\mathrm{R}_{1}$ 20 (coconut fiber) for each period A, B and C. Therefore, a set of volumetric maximum 21 growth rate $\left(v_{\max }\right)$ and half-saturation constant $\left(K_{S}\right)$ was assessed for each period (Table 22 1). For bacterial operation (Period A), a $v_{\max }$ of $815 \pm 290 \mathrm{~g}$ toluene $\mathrm{m}^{-3} \mathrm{~h}^{-1}$ was obtained 23 and a value of $5.01 \pm 2.95 \mathrm{~g} \mathrm{~m}^{-3}$ was determined for $K_{S}$. Results were in accordance with values found in the literature [27,28]. 
7 For fungal operation (Period C), a $v_{\max }$ of $5000 \pm 230 \mathrm{~g}$ toluene $\mathrm{m}^{-3} \mathrm{~h}^{-1}$ was found,

8 indicating that fungal operation presents a significant better capacity to biodegrade

9 toluene than bacteria. Thus, a higher $v_{\max }$ is in part due to the increment on nutrients

10 concentration that caused an increase in the biomass concentration, parameter that is

11 lumped into the $v_{\max }$. In the same way, low values of $K_{S}, 0.21 \pm 0.04 \mathrm{~g} \mathrm{~m}^{-3}$ were

12 calculated for Period $C$, demonstrating a higher affinity between the studied pollutant

13 and fungi than between the pollutant and bacteria. Previous works comparing kinetic

14 parameters between fungi and bacteria have not been found in the literature.

16 In the period of transition (Period B), the first sign of change in the behaviour of the 17 system was observed. The volumetric maximum growth rate obtained by optimization 18 was similar to that of Period A but the saturation constant decreased until $0.16 \pm 0.09 \mathrm{~g}$ $19 \mathrm{~m}^{-3}$. Though there was not a dominant population in the biofilter, a higher presence of 20 fungi was detected in the bioreactor. Thus, estimation of kinetic parameters in Period B 21 let to follow the evolution from bacterial to fungal operation by means of an increase in 22 the affinity between toluene and the microbial population. In comparison to this period 23 of transition, a better degradation capacity was obtained in Period C, according to the $24 \quad v_{\max }$ estimated. 
2 Outlet toluene concentration was accurately fit to experimental data (Figure 3)

3 through the evaluation of the objective function (Eq.8). Period $C$ needed a superior

4 number of iterations (data not shown) to search the minimum of the function due to a

5 higher number of experimental data.

6

7

8

9

10

Figure 3

12

13

14 It should be emphasized that the effects of potential changes in some parameters are

15 lumped in the estimated kinetic parameters. Owing to the system restrictions (only gas

16 phase is measured), the separate determination of additional parameter in both bacterial

17 and fungal operating periods could not be conducted. In order to include the potential

18 variation of the specific area, determination of this parameter in reactor 2 was

19 performed in the stage B where the evolution from bacterial to fungi was confirmed.

21 A sensitivity analysis of model parameters was performed in order to determine their

22 influence on model predictions (Table 2). This analysis revealed that the specific

23 surface area and the Henry coefficient are the most sensible parameters in the model.

24 Comparison of physicochemical parameters in bacterial and fungal consortia applied to

25 biofiltration has been only conducted for the partition coefficient [22]. They found that 
1 the partition coefficient (i.e. gas/biofilm) for a fungal biofilm was about 50 times lower

2 than that for a bacterial biofilm for an extremely hydrophobic compound. Although

3 potential variations in physicochemical parameters may lead to improve the removal

4 capacity of the reactors, an additional simulation was performed for the fungal period

5 (Period $C)$ to demonstrate that enhancement of the removal capacity is mainly due to

6 the modification of the microorganisms consortia in the reactors. (Figure 4). Simulation

7 results show that model predictions could not match experimental data by using the

8 same kinetic parameters found for the bacterial period and different, lower values of the

9 partition coefficient. $\mathrm{H}$ values ranging from 1 to 100 were used for the gas/water and

10 gas/biofilm ratios. Results demonstrated that the enhancement of the degradation

11 capacity of the biofilters is mainly related to the colonization of the filter bed by a

12 fungal consortium.

13

14

15

16

17

Table 2

18

19

20

21

22

Figure 4

23

24 The large confidence intervals assessed through the FIM method in all periods were

25 in great part due to the low quantity of experimental data measured in the whole 
1 operation time. In Period $C$, the relative errors associated to the optimized parameters

2 were estimated around $5 \%$ for $v_{\max }$ and $21 \%$ for $K_{S}$, according to the FIM method. In

3 Period $A$, the estimated confidence intervals reached values up to $36 \%$ and $59 \%$ for $v_{\max }$

4 and $K_{S}$, respectively. This is related to a lower sensitivity of the kinetic parameters in

5 model predictions according to the low biological degradation achieved during the

6 bacterial period (around 20\%). Thus, the low identifiability of kinetic parameters in

7 Period A clearly demonstrated that the physical behaviour of the reactor is correctly

8 described by mass transfer equations, according to predicted concentrations in

9 comparison to experimental data (Figure 3). For the same reason, a similar variability of

10 the inlet load in the whole operation period produces higher output fluctuations in

11 Period A than in Period C (Figure 3).

Model validation

Once the kinetic parameters were calibrated for $\mathrm{R}_{1}$ (coconut fiber), model validation was performed by comparing the simulation results to experimental data in $\mathrm{R}_{2}$ (pine leaves) for Period $A$ and Period $C$, in other words, for bacterial and fungal operation.

18 According to Baquerizo et al. (2005), results predicted by the model are strongly 19 dependent on the specific surface area available into the biofilter, which does not 20 correspond to that of the virgin packing material once biomass has grown over its 21 surface. In consequence, the specific surface area is the only physicochemical parameter 22 that needs to be separately determined for both reactors. Thus, prior to the validation 23 step, a specific surface area of $420 \mathrm{~m}^{2} \mathrm{~m}^{-3}$ was optimized by simulation from 24 experimental data in Period B for the pine leaves reactor, and further used for model 25 validation in the rest of periods (Figure 5). 


\section{Figure 5}

7

8 In case of $\mathrm{R}_{1}$, the specific surface area for coconut fiber for a colonized biofilter was

9 chosen in concordance to that reported by Baquerizo et al. (2005) for an almost identical

10 biofilter. Other physicochemical model parameters used in the present work are shown

11 in Table 3. Bed porosity was determined experimentally by standard methods [39].

Table 3. Physicochemical model parameters for $\mathrm{R}_{1}$ and $\mathrm{R}_{2}$

19 Model predictions for Period $A$ are shown in Figure $5 a$ illustrating a good 20 agreement with experimental data for the bacterial period. Moreover, the almost 21 constant removal efficiency shows the steady-state achieved in each period. In Figure $226 b$, simulated results for Period $C$ in the pine leaves reactor show that experimental data 23 is properly predicted by the model, even if the model predicts lower outlet toluene 24 concentration values in first days than those obtained experimentally. This is probably 25 explained by the biomass transition from bacteria to fungi because some bacteria might 
1 be still present in the reactor during the first days of Period $C$. Results are more

2 satisfactory at the end of the period indicating a pseudo biomass steady-state operation 3 in terms of biomass populations.

4

5

6

7

8

9

10

11 A statistic analysis based on a paired t-student test was evaluated in the validation process in order to quantify the agreement between results predicted by the model with

13 the optimized kinetic parameters and experimental data. The t-test executed on the

14 outlet toluene concentration yielded an absolute value of 0.93 for the validation in $R_{2}$. A

$15 \mathrm{t}$-value of 2.04 at $5 \%$ level of significance for 30 degrees of freedom [40] indicates that

16 the difference between outlet toluene concentration measured experimentally and outlet

17 toluene concentration predicted by the model are not statistically significant in the

18 whole operation. Thus, it could be certainty affirmed that periods were satisfactorily

19 described by the model under both bacteria and fungal operation.

\section{CONCLUSIONS}

23 A dynamic model to simulate toluene abatement by bacterial and fungal biofilters 24 has been developed, calibrated and validated through a set of different experimental conditions for biofilters with switching populations from bacteria to fungi. The model 
1 was able to predict satisfactorily different operation periods, including bacteria,

2 transition from bacteria to fungi, and fungi based operation be means of a small number

3 of parameters. Results clearly demonstrate that a higher complex model is not necessary

4 to describe properly the performance of the biofilter. However, a correct procedure in

5 biofilter modeling force to determinate model parameters for each situation instead of

6 taking them from literature. Moreover, the physico-chemical model was checked by

7 model predictions in the operation where biological degradation was not the

8 predominant process. Otherwise, estimation of kinetic parameters corroborated the

9 biomass evolved from bacteria to fungi in both biofilters in concordance to $\mathrm{pH}$ changes

10 reported along the entire experiment and microscopic observation. Kinetic parameters

11 confirmed that fungi provide a better capacity to degrade toluene from gas phase.

12 Moreover, a higher affinity was observed between fungi and the pollutant in comparison

13 to pollutant and bacteria consortium. Thus, determination of volumetric maximum

14 growth rate and semi saturation constant for both biofilters with their corresponding

15 confidence interval pointed out that biofilters colonized by fungi showed a better

16 performance than those colonized by bacteria. The model calibration was checked by a

17 novel procedure in gas biofilters modeling based on the Fisher Information Matrix and

18 the model validation was verified using a rigorous statistical test. Deviations on model

19 predictions are explained by biomass modification in the bioreactors obtaining better

20 results at the end of each period due to the pseudo biomass steady-state achieved.

\section{ACKNOWLEDGMENTS}

This work was supported by the Spanish CICYT project PPQ2003 - 02482. A.D.

25 Dorado received a predoctoral fellowship from the M.E.C. (Ministerio de Educación y 
1 Ciencia). The discussion with Dr. Juan Antonio Baeza Labat from the Department of

2 Chemical Engineering at UAB and Dr. Josep $\mathrm{M}^{\mathrm{a}}$ Rosell Garriga from the Department of 3 Applied Mathematics at UPC are gratefully acknowledged.

4

References

6

7 1. van Groenestijn, J.W. and Kraakman, N.J.R. Recent developments in biological 8 waste gas purification in Europe. Chem. Eng. J. 113 (2-3) (2005) 85-91.

9 2. Delhomenie, M.C. and Heitz, M. Biofiltration of air: A review. Crit. Rev. Biotechnol. $1025(1-2)(2005) 53-72$.

11 3. Baquerizo, G.; Maestre, J.P.; Sakuma, T.; Deshusses, M.A.; Gamisans, X.; Gabriel, 12 D.; Lafuente, J. A detailed model of a biofilter for ammonia removal: Model parameters 13 analysis and model validation. Chem. Eng. J. 113 (2-3) (2005) 205-214.

14 4. Devinny, J.S.; Deshusses, M.A.; Webster, T.S. Biofiltration for air pollution control. 15 Lewis Publishers: New York, Vol. 1 (1999) pp. 299.

16 5. García-Peña, E.I.; Hernández, S.; Favela-Torres, E.; Auria, R.; Revah, S. Toluene 17 biofiltration by the fungus Scedosporium apiospermum TB1. Biotechnol. Bioeng. 76 (1) 18 (2001) 61-69.

19 6. Cox, H.H.J., Moerman, R.E.; vanBaalen, S.; vanHeiningen, W.N.M.; Doddema, H.J.;

20 Harder, W. Performance of a styrene-degrading biofilter containing the yeast Exophiala 21 jeanselmei. Biotechnol. Bioeng. 53 (3) (1997) 259-266. 
1 7. van Groenestijn, J.W.; van Heiningen, W.N.M.; Kraakman, N.J.R. Biofilters based on

2 the action of fungi. Water Sci. Technol. 44 (9) (2001) 227-232.

3 8. Nikiema, J.; Bibeau, L.; Lavoie, J.; Brzezinski, R.; Vigneux, J.; Heitz, M.

4 Biofiltration of methane: An experimental study. Chem. Eng. J. 113 (2-3) (2005) 1115117.

6 9. Delhomenie, M.C.; Bibeau, L.; Gendron, J.; Brzezinski, R.; Heitz, M. A study of 7 clogging in a biofilter treating toluene vapors. Chem. Eng. J. 94 (3) (2003) 211-222.

8 10. Acuña, M.E.; Pérez, F.; Auria, R.; Revah, S. Microbiological and kinetic aspects of 9 a biofilter for the removal of toluene from waste gases. Biotechnol. Bioeng. 63 (2) $10 \quad$ (1999) 175-184.

11 11. Matteau, Y. and Ramsay, B. Active compost biofiltration of toluene. Biodegrad. 8 12 (3) (1997) 135-141.

13 12. Maestre, J.P.; Gamisans, X.; Gabriel, D.; Lafuente, J. Fungal biofilters for toluene 14 biofiltration: evaluation of the performance with four packing materials under different 15 operating conditions. Chemosphere 67 (2007) 684-692.

16 13. Aizpuru, A.; Dunat, B.; Christen, P.; Auria, R.; García-Peña, I.; Revah, S. Fungal 17 biofiltration of toluene on ceramic rings. J. Environ. Eng. 131 (3) (2005) 396-402.

18 14. Spigno, G.; Pagella, C.; Fumi, M.D.; Molteni, R.; De Faveri, D.M. VOCs removal 19 from waste gases: gas-phase bioreactor for the abatement of hexane by Aspergillus 20 niger. Chem. Eng. Sci. 58 (3-6) (2003) 739-746.

21 15. van Groenestijn, J.W.; Liu, J.X. Removal of alpha-pinene from gases using 22 biofilters containing fungi. Atmos. Environ. 36 (35) (2002) 5501-5508. 
1 16. Weber, F.J.; Hartmans, S. Prevention of clogging in a biological trickle-bed reactor

2 removing toluene from contaminated air. Biotechnol. Bioeng. 50 (1) (1996) 91-97.

3 17. Woertz, J.R.; Kinney, K.A.; McIntosh, N.D.P.; Szaniszlo, P.J. Removal of toluene

4 in a vapor-phase bioreactor containing a strain of the dimorphic black yeast Exophiala

5 lecanii-corni. Biotechnol. Bioeng. 75 (5) (2001) 550-558.

6 18. Nikolova, N. and Nenov, V. BTEX degradation by fungi. Water Sci. Technol. 51 $7 \quad$ (11) (2005) 87-93.

8 19. Estevez, E.; Veiga, M.C.; Kennes, C. Biofiltration of waste gases with the fungi 9 Exophiala oligosperma and Paecilomyces variotii. Appl. Microbiol. Biotechnol. 67 (4) 10 (2005) 563-568.

11 20. Moe, W.M. and Qi, B. Performance of a fungal biofilter treating gas-phase solvent 12 mixtures during intermittent loading. Water Res. 38 (9) (2004) 2259-2268.

13 21. Vergara-Fernandez, A.; Van Haaren, B.; Revah, S. Phase partition of gaseous 14 hexane and surface hydrophobicity of Fusarium solani when grown in liquid and solid 15 media with hexanol and hexane. Biotechnol. Lett. 28 (24) (2006) 2011-2017.

16 22. Arriaga, S.; Revah, S. Removal of n-hexane by Fusarium solani with a gas-phase 17 biofilter. J. Ind. Microbiol. 32 (11-12) (2005) 548-553.

18 23. Abumaizar, R.J.; Smith, E.H.; Kocher, W. Analytical model of dual-media biofilter 19 for removal of organic air pollutants. J. Environ. Eng. 123 (6) (1997) 606-614.

20 24. Amanullah, M.; Farooq, S.; Viswanathan, S. Modeling and simulation of a biofilter. 21 Ind. Eng. Chem. Res. 38 (7) (1999) 2765-2774. 
1 25. Metris, A.; Gerrard, A.M.; Cumming, R.H.; Weigner, P.; Paca, J. Modelling shock

2 loadings and starvation in the biofiltration of toluene and xylene J. Chem. Technol.

3 Biotechnol. 76 (6) (2001) 565-572.

4 26. Ottengraf, S. and Van der Oever, HC. Kinetics of organic compunds removal from

$5 \quad$ waste gases with a biological filter. Biotechnol. Bioeng. 25 (1983) 3089-3102.

6 27. Shareefdeen, Z. and Baltzis, B.C. Biofiltration of toluene vapor under steady-state 7 and transient conditions: Theory and experimental results. Chem. Eng. Sci. 49 (24A) 8 (1994) 4347-4360.

9 28. Zarook, S.M.; Shaikh, A.A.; Ansar, Z. Development, experimental validation and 10 dynamic analysis of a general transient biofilter model. Chem. Eng. Sci. 52 (5) (1997) $11 \quad 759-773$.

12 29. Alonso, C.; Zhu, X.; Suidan, M.T.; Kim, B.R.; Kim, B.J. Parameter estimation in 13 biofilter systems. Environ. Sci. Technol. 34 (11) (2000) 2318-2323.

14 30. Bhat, T.R.; Venkataramani, D.; Ravi, V.; Murty, C.V.S. An improved differential 15 evolution method for efficient parameter estimation in biofilter modeling. Biochem. 16 Eng. J. 28 (2) (2006) 167-176.

17 31. Guisasola, A.; Baeza, J.A.; Carrera, J.; Sin, G.; Vanrolleghem, P.A.; Lafuente, J. 18 The influence of experimental data quality and quantity on parameter estimation 19 accuracy. Educ. Chem. Eng. 1 (1) (2006) 139-145. 32. Deshusses, M.A.; Hamer, G.; Dunn, I.J. Behaviour of biofilters for waste air

21 biotreatment. 1. Dynamic model development. Environ. Sci. Tecnol. 29 (4) (1995) 221048. 
1 33. Hodge, D.S. and Devinny, J.S. Modeling removal of air contaminants by

2 biofiltration. J. Environ. Eng. 121 (1) (1995) 21-32.

3 34. Morales, M.; Hernandez, S.; Cornabe, T.; Revah, S.; Auria, R. Effect of drying on

4 biofilter performance: Modeling and experimental approach. Environ. Sci. Technol. 37

$5 \quad$ (5) (2003) 985-992.

6 35. Mohseni, M. and Allen, D.G. Biofiltration of mixtures of hydrophilic and 7 hydrophobic volatile organic compounds. Chem. Eng. Sci. 55 (9) (2000) 1545-1558.

8 36. Mehra, R.K. Optimal input signals for parameter estimation in dynamic systems, 9 survey and new results. IEEE Trans. Autom. Control 19 (6) (1974) 753-768.

10 37. Dochain, D. and Vanrolleghem, P.A. Dynamical modeling and estimation in 11 wastewater treatment processes. IWA Publishing: London, UK, Vol. 1 (2001) pp. 342.

12 38. Prenafeta-Boldu, F.X.; Luykx, D.M.A.M.; Vervoort, J. Bont, J.A.M. Fungal 13 metabolism of toluene: Monitoring of fluorinated analogs by F-19 nuclear magnetic 14 resonance spectroscopy. Appl. Environ. Microbiol. 67 (3) (2001) 1030-1034.

15 39. Leege, P.B. and Thompson, W.H. Test methods for the examination of composting 16 and compost. US Composting Council: Bethesda, Vol. 1 (1995) pp. 350.

17 40. Mendenhall, W. and Sincich, T. Probabilidad y estadística para ingeniería y 18 ciencias. Prentice Hall: México, Vol. 1 (1997) pp. 739. 